\title{
Early detection of neovascular age-related macular degeneration: an economic evaluation based on data from the EDNA study
}

\section{Authors:}

Rodolfo Hernández ${ }^{1}$, Charlotte Kennedy ${ }^{1}$, Katie Banister ${ }^{2}$, Beatriz Goulao ${ }^{2}$, Jonathan Cook ${ }^{3}$, Sobha Sivaprasad ${ }^{4}$, Ruth Hogg ${ }^{5}$, Augusto Azuara-Blanco ${ }^{5}$, Heinrich Heimann ${ }^{6}$, Maria Dimitrova $^{7}$, Richard Gale ${ }^{8,9}$, Mia Porteous ${ }^{8}$, Craig Ramsay ${ }^{2}$, Usha Chakravarthy ${ }^{5}$, Graham Scotland ${ }^{1,2}$.

\section{Affiliations:}

1. University of Aberdeen, Health Economics Research Unit, Aberdeen, UK.

2. University of Aberdeen, Health Services Research Unit, Aberdeen, UK.

3. University of Oxford, Nuffield Department of Population Health, Oxford, UK.

4. NIHR Moorfields Biomedical Research Centre, London, Greater London, UK.

5. Queen's University Belfast, Centre for Public Health Belfast, Belfast, UK

6. Liverpool University Hospitals NHS Foundation Trust, St Paul's Eye Unit, Liverpool, $\mathrm{UK}$

7. NHS Healthcare Improvement Scotland, Gyle Square, Edinburgh, UK.

8. York Teaching Hospital NHS Foundation Trust, Ophthalmology, York, North Yorkshire, UK

9. University of York, Department of Health Sciences, York, North Yorkshire, UK

Correspondence to: Dr Graham Scotland, Health Economics Research Unit, University of Aberdeen, Foresterhill, Aberdeen AB25 2ZD, UK (Email: g.scotland@abdn.ac.uk)

Word count: 3,498

\section{Contribution of authors:}

Rodolfo Hernández (Research Fellow, Health Economics) developed the model and conducted the economic analysis. Charlotte Kennedy conducted the costing survey and analyses of post-conversion visual acuity data to inform key model inputs. Katie Banister (Research Fellow, Trial Management) contributed to the conception and design of the study and was responsible for its day-to-day conduct and management. Beatriz Goulão (Research Fellow, Statistics) conducted the statistical analyses which informed the time to conversion 
and diagnostic accuracy inputs for the economic model. Jonathan A Cook (Associate Professor, Statistics) contributed to the conception and design of the study and was responsible for the statistical analysis of time to conversion and diagnostic accuracy. Sobha Sivaprasad (Consultant, Ophthalmology), Ruth Hogg (Senior Lecturer, Vision Science) Augusto Azuara-Blanco (Consultant, Ophthalmology), and Heinrich Heimann (Consultant, Ophthalmology) all contributed to the conception and design of the study and provided clinical expertise and insights to inform key modelling assumptions. Maria Dimitrova contributed to the development of the economic model. Richard Gale (Consultant, Ophthalmology), Chief investigator of the parallel FASBAT study, provided clinical expertise and data to inform key model inputs and assumptions. Mia Porteous (Trial Manager for the FASBAT study) was responsible for the collection of post conversion visual acuity and treatment data for EDNA participants who subsequently converted and enrolled in the FASTBAT study (used to inform key modelling inputs). Craig Ramsay (Professor, Health Care Evaluation), Co-Chief Investigator of EDNA, contributed to the conception and design of the study and was methodological lead for the study. Usha Chakravarthy (Consultant, Ophthalmology), Chief Investigator of EDNA, led the conception and design of the study and the recruitment and follow-up of participants. Graham Scotland (Reader, Health Economics) contributed to the conception and design of the study, was responsible for the health economic objectives, and led the writing of this manuscript. All authors contributed to the interpretation of the results and critical revision of the manuscript for submission. 


\section{SYNOPSIS}

This economic modelling study suggests that spectral-domain optical coherence tomography offers a cost-effective monitoring test for detecting the onset of neovascular age-related macular degeneration in the second eye of people being treated for unilateral disease. 


\begin{abstract}
Background/Aims: To evaluate the cost-effectiveness of non-invasive monitoring tests to detect the onset of neovascular age-related macular degeneration (nAMD) in the unaffected second eye of patients receiving treatment for unilateral nAMD in a UK NHS hospital outpatient setting.

Methods: A patient-level state transition model was constructed to simulate the onset, detection, and treatment of nAMD in the second eye. Five index tests were compared: self-reported change in visual function, Amsler test, clinic measured change in visual acuity from baseline, fundus assessment by clinical examination or colour photography, and spectral domain optical coherence tomography (SDOCT). Diagnosis of nAMD was confirmed by fundus fluorescein angiography (FFA) before prompt initiation of anti-vascular endothelial growth factor treatment. Quality adjusted life years (QALYs) and costs of health and social care were modelled over a 25-year time horizon.
\end{abstract}

Results: SD-OCT generated more QALYs (SD-OCT, 5.830; fundus assessment, 5.787; Amsler grid, 5.736, patient's subjective assessment, 5.630; and visual acuity, 5.600) and lower health and social care costs (SD-OCT, £19,406; fundus assessment, £19,649; Amsler grid, £19,751; patient’s subjective assessment, $£ 20,198$; and visual acuity, $£ 20,444$ ) per patient compared to other individual monitoring tests. Probabilistic sensitivity analysis indicated a high probability (97-99\%) of SD-OCT being the preferred test across a range of cost-effectiveness thresholds (£13,000-£30,000) applied in the UK NHS.

Conclusions: Early treatment of the second eye following FFA confirmation of SD-OCT positive findings is expected to maintain better visual acuity and health related quality of life and reduce costs of health and social care over the lifetime of patients.

Keywords: age-related macular degeneration; cost-effectiveness; health economics 


\section{INTRODUCTION}

Neovascular age-related macular degeneration (nAMD) causes severe visual loss and is the most common cause of blindness in persons aged 50 years or over in the western world. ${ }^{1}$

Visual acuity (VA) outcomes for people with nAMD have improved in recent years with the introduction of therapies targeting vascular endothelial growth factor (VEGF). ${ }^{2,3}$ However, there remains a substantial residual burden of visual morbidity. The UK based IVAN trial, for example, which achieved longer-term follow-up of $99 \%$ of eligible patients following release from the trial protocol at two years, showed that eyes monitored and treated in routine practice (median follow-up of 3.3 years) lost distance visual acuity at a rate of 4.3 ETDRS letters per year. ${ }^{4}$ Furthermore, $20 \%$ had VA worse than 33 letters at the end of study eye monitoring.

A high incidence of second eye involvement (8-10\% per year), ${ }^{5}$ coupled with real world evidence showing that second eyes with good vision at treatment initiation maintain better VA over three years than first presenting eyes, ${ }^{6}$ provides strong rationale for closely monitoring the second eye of patients being treated for nAMD in one eye. There is a clear need for an easily and rapidly performed cost-effective monitoring test that will detect the onset of nAMD in the second eye with high diagnostic accuracy.

This paper reports on an economic evaluation conducted as part of the UK based EDNA study (Early Detection of Neovascular Age-related macular degeneration), which assessed the diagnostic monitoring performance of five candidate tests against a reference standard of fundus fluorescein angiography (FFA) over a 36-month follow-up period. ${ }^{7}$

\section{METHODS}

A patient-level state transition model was developed to simulate the long-term impact of candidate monitoring tests, carried out in UK NHS outpatient eye services, on visual acuity outcomes and health and social care costs over a 25 year time horizon. The model focused on the second eye of people commencing treatment for nAMD in one eye, and was structured around disease, diagnosis, and treatment status (Figure 1). Individuals were simulated to pass through the model one at time using a monthly cycle. Visual acuity (VA) was modelled as a continuous variable, and the second eye (EDNA study eye) was assumed to remain stable up 
to the point of conversion. It was also assumed that the second eye represented the best seeing eye (BSE) over the modelled time horizon.

\section{[Figure 1 here]}

\section{Population}

The baseline characteristics of simulated individuals were drawn at random from a table containing the baseline characteristics of each EDNA study participant $(n=552)$. The average age was 77.4 years, mean baseline VA in the unaffected second eye was 79 letters compared to 56.6 in the first eye, and $57.2 \%$ were female.

\section{Comparators}

The model compared the monitoring tests under investigation in the EDNA study: SD-OCT (abnormal findings, indicative of nAMD), fundus evaluation (slit lamp biomicroscopy or fundus photography showing clinical signs of nAMD as determined by an expert), Amlser grid test (distortion or regions where the grid pattern disappears when previously no distortion present), patient subjective change in VA (much worse than the previous visit), and visual acuity (reduction of 10 or more letters in best corrected visual acuity from baseline). A secondary analysis also assessed the cost-effectiveness of the test combination with highest sensitivity (SD-OCT and fundus evaluation) and a test combination of all tests excluding OCT. The base case assumed that positive tests would be confirmed with FFA (the reference standard in the EDNA study) prior to treatment initiation.

\section{Time to conversion}

During the EDNA study, the second eye of 120 participants converted to nAMD as confirmed by local interpretation of FFA, and an additional 25 participants had a clinical determination of conversion without FFA, yielding a crude conversion rate of $26 \%$ (95\% CI $22.3 \%, 30.6 \%$ ) with a median follow-up time of 33 months (ranging from 0.8 to 38.5 months). Parametric survival analysis of time to conversion was conducted using local interpretation of FFA to define events. Individuals were censored at the time of their last observed FFA if no FFA-confirmed conversion was observed. An exponential curve was identified as having the best statistical fit to the observed data and was used in the model (Supplementary figure 1). Weibull and the log-normal distributions were tested in sensitivity analysis. 


\section{Time to losing ten or more ETDRS letters (without treatment)}

Following conversion of the second eye, time to deterioration of VA in the absence of treatment was informed by post-conversion visual acuity data on the 145 patients who converted during EDNA. VA data at time of treatment initiation and at one-year postconversion were obtained with permission from the parallel FASBAT study ${ }^{8}$ or routine case notes. Time of conversion was taken as the midpoint between the visit at which nAMD was detected and the preceding visit. Time at risk was calculated as the time from conversion to losing ten or more letters or treatment initiation (whichever came first). If no treatment was initiated, time at risk was censored at the last available follow-up point where VA data were available.

The data were used to generate a Kaplan Maier curve, to which parametric survival functions were fitted (Supplementary Figure 2). Given uncertainty around the exact timing of events and the shape of the distribution, we selected the exponential curve for the base case extrapolation.

We then used the difference in VA between the first presenting eye and the second eye (EDNA study eye) at baseline as a proxy to estimate the proportion of first presenting eyes that had lost 10 or more letters and 30 or more letters between conversion and treatment initiation; $78.4 \%$ and $29.2 \%$ respectively. It was assumed that untreated, $29.2 \%$ of second eyes can be expected to have lost 30 or more letters by the time $78.4 \%$ have lost 10 or more letters (15.15 months based on extrapolation). We used the relative difference to approximate a curve for time to losing 30 or more letters (supplementary Figure 2). Exact numbers of letters lost were drawn randomly from a uniform distribution (minimum 10, maximum 29) for those modelled to lose 10-29 letters, and from a gamma distribution (mean $=42$, standard deviation $=9.27$, minimum $=30$ ) for those losing 30 letters or more prior to treatment initiation; again, informed by the difference between the first presenting eye and the EDNA study eye at baseline.

\section{Diagnostic accuracy}

Test sensitivity and specificity were derived from the EDNA analysis of index test results at the last study visit when everyone received an FFA. However, test specificities were adjusted 
to account for lack of independence between repeated test observations within individuals (Table 1).

Since the cost-effectiveness modelling was based on expected changes in VA following conversion to $\mathrm{nAMD}$, and VA loss $\geq 10$ letters was one of the index tests, we assumed VA change to have zero sensitivity for nAMD prior to any VA loss, and $100 \%$ sensitivity following VA loss $\geq 10$ letters.

Table 1 Diagnostic accuracy estimates applied in the economic model

\begin{tabular}{|l|r|r|r|r|r|}
\hline Index test & $\begin{array}{r}\text { Sensitivity (\%) } \\
(\mathbf{9 5 \%} \text { CI) }\end{array}$ & $\begin{array}{r}\text { Specificity (\%) } \\
\mathbf{( 9 5 \%} \mathbf{C I})\end{array}$ & $\begin{array}{r}\text { Cumulative } \\
\text { proportion } \\
\text { experiencing } \\
\text { a false } \\
\text { postive } \\
\text { during } \\
\text { EDNA }^{\mathbf{a}}\end{array}$ & $\begin{array}{r}\text { Mean no. } \\
\text { of tests in } \\
\text { EDNA } \\
\text { study }\end{array}$ & $\begin{array}{r}\text { Adjusted } \\
\text { specificities } \\
\text { per test }^{\mathbf{b}}\end{array}$ \\
\hline Amsler & $26.5(18.8,36.1)$ & $93.7(90.1,96.1)$ & 0.1398 & 13.8 & 0.9891 \\
\hline Fundus & $49.6(40.8,58.4)$ & $99.7(98.2$, & 0.02 & 14.2 & 0.9986 \\
\hline OCT & $90.0(83.2,94.3)$ & $96.4(93.8,98.0)$ & 0.0965 & 14.5 & 0.9930 \\
\hline $\begin{array}{l}\text { Self-reported } \\
\text { vision }\end{array}$ & $4.2(1.6,9.8)$ & $98.5(96.4,99.5)$ & 0.0177 & 14 & 0.9987 \\
\hline Visual acuity & $25.8(18.8$, & $88.4(84.5,91.4)$ & 0.182 & 15.5 & 0.9871 \\
\hline OCT or Fundus & $92.4(86.1,96.1)$ & $96.1(93.4,97.8)$ & $0.140^{+}$ & $17.6^{+}$ & $0.9915^{+}$ \\
\hline $\begin{array}{l}\text { All tests } \\
\text { excluding OCT }\end{array}$ & $63.9(54.0,72.8)$ & $85.9(81.2,89.6)$ & $0.444^{+}$ & $17.6^{+}$ & $0.9673^{+}$ \\
\hline
\end{tabular}

${ }^{a}$ Proportion of patients coded as false positive for each test at any testing visit throughout the EDNA study; ${ }^{\mathrm{b}}$

Adjusted specificity calculated as $=(1-a)^{\wedge}(1 /$ mean number of tests $)$, so that its application over the observed mean number of tests in EDNA yielded the observed cumulative proportion experiencing a false positive on each test; +Adjusted specificities for combinations were calculated using the cumulative proportion of nonconvertors experiencing a false positive over follow-up, and the expected number of tests over 36 months of monitoring; ' represents overall sensitivity of the VA test for detecting observed EDNA cases, which is combination of $100 \%$ sensitivity for detecting cases that had lost ten or more letters from baseline, and $0 \%$ sensitivity for cases that had not. 


\section{Post-treatment visual acuity trajectories}

For eyes that had lost 10 or more letters prior to treatment initiation, an average improvement in VA of +6.47 (95\% CI: 2.66 - 10.28) was applied over the loading phase (EDNA postconversion data). For those commencing treatment prior to losing 10 or more letters, the average change in VA over the loading phase was assumed zero (Supplementary Table 1). External literature shows that second eyes with good VA at treatment initiation, on average do not accrue any significant improvement in VA over the loading phase, but maintain better VA at two to three years compared to eyes with poorer VA at treatment initiation. ${ }^{6,9}$ Postloading phase changes in VA were informed primarily by data from the ranibizumab arm of the UK based IVAN trial. ${ }^{10,11}$ Following the approach described by Claxton et al., ${ }^{12}$ we applied random draws from time dependent normal distributions for VA change per month (Supplementary Table 1). Beyond 24 months, we specified a monthly VA change distribution based on the annual rate of decline in distance VA observed during the long-term follow-up of IVAN participants; 4.3 letters per year (95\% confidence interval: 3.7 to 4.9). Mean VA trajectories for eyes treated before and after significant vision loss ( $\geq 10$ letters) are provided in Supplementary Figure 3.

\section{Treatment discontinuation}

Monthly probabilities of treatment discontinuation were applied from 24 months following treatment initiation (Supplementary Table 2). ${ }^{4}$ We further assumed that treatment and monitoring would cease for futility if vision dropped below 18 letters. For those who discontinued treatment with VA better than 18 letters, stability was assumed and no further changes in VA were modelled unless reactivation and re-initiation of treatment ocurred.

Since data on the rate of treatment re-initiation were not available from IVAN, we informed this using data provided by the authors of another UK based cohort study (Personal communication, Sobha Sivaprasad, March 2020) ${ }^{13}$ (Supplementary Table 2).

\section{Valuation of visual acuity outcomes}

Health state utility data by VA status was identified from searches of the published literature. ${ }^{14-22},{ }^{23}$ For consistency with the NICE appraisals of ranibizumab and aflibercept, ${ }^{24,25}$ we applied utilities reported by Czoski-Murray et al. ${ }^{22}$ based on UK general population time trade-off values for visual impairment states simulated using contact lenses. In line with the NICE appraisals, we used the published equation based on regression analysis of this data to assign health state utility weights in the model (Supplementary Table 3) 


\section{Resource use and costs}

The model included costs of testing and monitoring for conversion to $\mathrm{AMD}$, monitoring and treatment post conversion, and health and personal social care associated with severe visual loss. All costs were expressed in 2018/2019 UK Sterling, inflated when required using the NHS cost inflation index. ${ }^{26}$

For each test, we assessed the time required to perform it and the time required to interpret it, for both eyes and for one eye. The times required and the grades of staff performing each role were based on a survey of centres participating in EDNA (18 of 24 responding), and these were combined with published unit cost multipliers for hospital staff (inclusive of overheads). ${ }^{26}$ Prices of test specific equipment, obtained from centres or manufacturers, were annuitized over their expected useful life span, and allocated on a per test basis using reported throughput. Equipment costs per patient were further allocated between the first and second eye based on the estimated time required to test the first and second eye.

Since monitoring of the second eye (EDNA study eye) coincided with monitoring of the treated (first presenting) eye, the marginal cost of assessing the second eye with each test was estimated and applied on top of the cost of a standard outpatient monitoring visit (Supplementary Table 4). ${ }^{27}$ The frequency of testing was based on observed average time interval between tests in EDNA, which increased over the 36 month follow-up. This equated to seven tests in year one, six in year two, and five in year three. In subsequent years we carried forward the frequency observed in the final 6 months of EDNA (four per patient year) out to five years. Beyond five years, it was assumed that monitoring for conversion of the second eye would continue at a reduced frequency of twice per year, and the cost of testing one eye was applied from this point onwards (assuming the majority of first treated eyes would be discharged from treatment by this time). We also assessed a scenario which assumed no further monitoring for conversion from five years.

Following conversion of the second eye, treatment and monitoring costs were applied according to time since treatment initiation (supplementary Table 5). 
Where vision dropped below 35 letters, health and social care costs associated with legal blindness were applied. ${ }^{28}$ Unit costs of post-conversion monitoring and treatment are provided in supplementary Table $6 . .^{27,29,30}$

\section{Analysis methods}

Monte Carlo simulation was used to propagate the passage of 200,000 individuals through the model. Future costs and QALYs were discounted a rate of $3.5 \%$ beyond year one. ${ }^{31}$

Incremental cost-effectiveness ratios, expressing the additional cost per QALY gained, were estimated by comparing each testing strategy to the next less costly strategy (excluding those found to be more costly and less effective than an alternative option).

Probabilistic sensitivity analysis was performed by assigning probability distributions to each input parameter based on reported means and measures of variance in the accompanying Tables. Beta distributions were assigned to sensitivity and specificity parameters, gamma distributions were used for costs of testing and blindness (assuming a standard error of $10 \%$ of the mean), and normal distributions were applied to all other parameters. The PSA used 5000 first order simulations for each of 1,000 random draws from the assigned second order probability distributions. The output from this analysis provides the probability of each monitoring test being preferred by increasing cost-effectiveness thresholds. ${ }^{32}$ Further deterministic scenario analysis was undertaken to assess the impact on findings of uncertainty arising from key structural assumptions (Supplementary Table 7). 


\section{RESULTS}

The results of the base case analysis indicate that more sensitive monitoring tests generate increased health benefits at a lower cost, with SD-OCT being most effective and least costly and VA change being least effective and most costly, and (Table 2).

Table 2 Base case cost-effectiveness results

\begin{tabular}{|l|c|c|c|c|c|}
\hline Strategy & Cost & $\begin{array}{c}\text { Incremental } \\
\text { Costs }\end{array}$ & QALYs & $\begin{array}{c}\text { Incremental } \\
\text { QALYs }\end{array}$ & ICER \\
\hline OCT & 19,406 & & 5.830 & & \\
\hline $\begin{array}{l}\text { Fundus clinical } \\
\text { evaluation }\end{array}$ & 19,649 & 243 & 5.787 & -0.044 & $-5,562^{* *}$ \\
\hline Amsler & 19,751 & 346 & 5.736 & -0.095 & $-3,656^{* *}$ \\
\hline Self-reported vision & 20,198 & 792 & 5.630 & -0.200 & $-3,961^{* *}$ \\
\hline Visual acuity & 20,444 & 1,039 & 5.600 & -0.230 & $-4,510^{* *}$ \\
\hline
\end{tabular}

**Absolutely dominated

The index tests with lower sensitivity and specificity accrue higher pre-diagnosis costs than more sensitive / specific strategies due to more visits prior to detection and increased chances of a false positive result (Supplementary Table 8). More sensitive index tests accumulate higher post-diagnosis monitoring and treatment costs resulting from earlier detection. The increased costs of earlier treatment, however, are more than offset by reduced costs associated with visual impairment and blindness.

The modelling suggests that compared to using VA alone, SD-OCT monitoring brings detection forward by approximately 7.5 months, for a mean gain in VA at time of treatment initiation of approximately 16 letters (Table 3). It is this earlier initiation of treatment and maintenance of better VA that drives the QALY gains for SD-OCT compared to the other strategies. 
Table 3 Model output: time lags from conversion to detection and 1st treatment and visual acuity at first treatment

\begin{tabular}{|c|c|c|c|c|}
\hline \multirow{3}{*}{ Strategy } & \multicolumn{3}{|c|}{ Time difference (months) } & \multirow[b]{2}{*}{$\begin{array}{c}\text { Visual Acuity at } \\
\text { 1st treatment }\end{array}$} \\
\hline & $\begin{array}{c}\text { Conversion to } \\
\text { nAMD to detection }\end{array}$ & $\begin{array}{c}\text { Conversion to nAMD } \\
\text { to } 1 \text { st treatment } \\
\end{array}$ & $\begin{array}{c}\text { Detection to } \\
\text { 1st Treatment }\end{array}$ & \\
\hline & mean $(\mathrm{sd})$ & mean $(\mathrm{sd})$ & mean $(\mathrm{sd})$ & mean $(\mathrm{sd})$ \\
\hline OCT & $2.5(1.8)$ & $3.3(1.8)$ & $0.8(0.4)$ & $71.3(13.4)$ \\
\hline $\begin{array}{l}\text { Fundus clinical } \\
\text { evaluation }\end{array}$ & $4.1(3.7)$ & $4.8(3.7)$ & $0.7(0.5)$ & $68(14.6)$ \\
\hline Amsler & $5.9(5.4)$ & $6.4(5.4)$ & $0.5(0.5)$ & $64.4(15.1)$ \\
\hline $\begin{array}{l}\text { Self-reported } \\
\text { vision }\end{array}$ & $9.4(8.4)$ & $9.5(8.4)$ & $0.1(0.3)$ & $57.2(13.3)$ \\
\hline Visual acuity & $10(9.2)$ & $10.2(9.2)$ & $0.2(0.4)$ & $55.2(11.8)$ \\
\hline
\end{tabular}

Results of the probabilistic sensitivity analysis show consistency with the base case deterministic results (Supplementary Table 9). The cost-effectiveness acceptability curves (Figure 2) indicate that SD-OCT has a very high chance of being the preferred strategy across a range of cost-effectiveness thresholds typically applied by NHS decision making bodies.

\section{[Figure 2 here]}

The results of the scenario analyses detailed in supplementary Table 7 are reported in supplementary Table 10. They indicate that the ICER for SD-OCT remains below $£ 20,000$ per QALY for all the scenarios tested.

In a scenario in which treatment is withheld until vision drops below 70 letters, the QALY gain associated with SD-OCT is diminished and its ICER increases to $£ 19,488$ (Supplementary Table 10, scenario 15). However, it can be noted that this delayed treatment strategy results in greater costs and lower QALYs compared to the base case which assumes immediate initiation of treatment. Similarly, the base case strategy of confirming SD-OCT positive results with an FFA prior to treatment initiation is less costly and of equal efficacy to the alternative strategy of treating all OCT positive cases without a confirmatory FFA (supplementary Table 10, scenario 16). 
In a secondary analysis, we assessed cost-effectiveness when including two combination strategies: 1) positive findings on SD-OCT or fundus examination counting as a positive result; and 2) positive findings on any test apart from OCT counting as a positive result (Table 4). The combined SD-OCT/fundus strategy generates a very small QALY gain over SD-OCT alone. However, the increased testing cost results in the ICER being above accepted cost-effectiveness thresholds. The combination of all other tests, excluding OCT, generates higher costs and lower QALYs compared to OCT on its own and in combination with fundus evaluation (Table 4).

Table 4 Cost-effectiveness results including the combination of OCT and fundus evaluation

\begin{tabular}{|l|c|c|c|c|c|}
\hline Strategy & Cost & $\begin{array}{l}\text { Incremental } \\
\text { Costs }\end{array}$ & QALYs & $\begin{array}{l}\text { Incremental } \\
\text { QALYs }\end{array}$ & ICER \\
\hline OCT & $£ 19,406$ & & 5.830 & & \\
\hline Fundus evaluation & $£ 19,649$ & $£ 243$ & 5.787 & -0.044 & $-£ 5,560^{* *}$ \\
\hline $\begin{array}{l}\text { Test combination } \\
\text { (OCT+Fundus) }\end{array}$ & $£ 19,729$ & $£ 323$ & 5.833 & 0.002 & $£ 137,711$ \\
\hline Amsler grid & $£ 19,752$ & $£ 23$ & 5.736 & -0.097 & $-£ 233^{* *}$ \\
\hline Patient's subjective assessment & $£ 20,199$ & $£ 470$ & 5.630 & -0.202 & $-£ 2,320^{* *}$ \\
\hline Test combination (no OCT) & $£ 20,203$ & $£ 473$ & 5.806 & -0.027 & $-£ 17,557^{* *}$ \\
\hline Visual acuity & $£ 20,445$ & $£ 716$ & 5.600 & -0.233 & $-£ 3,076^{* *}$ \\
\hline
\end{tabular}

**Absolutely dominated 


\section{DISCUSSION}

The results of this study suggest that of the individual tests that were assessed, SD-OCT can be expected to generate the most quality adjusted life years and lowest health and social care costs when used to monitor the second eye of patients with unilateral nAMD. The increased costs associated with earlier detection and treatment are offset by a reduction in the costs which are associated with severe visual impairment. The QALY gains for SD-OCT are driven by the maintenance of better visual acuity in the second eye due to earlier detection, allowing earlier treatment initiation.

By adopting an individual simulation approach, we were able to model VA as a continuous variable, which ensured the model outputs were sensitive to changes in VA. Key inputs including time to conversion and diagnostic accuracy were informed by the prospective EDNA study. In addition, resource use associated with pre-conversion monitoring was based on a survey of centres participating in the EDNA study, and post-detection treatment costs were based on pragmatic NHS based trials, supporting the generalisability of the model findings to the NHS. Finally, post-treatment VA changes were also carefully informed by a range of sources applicable to NHS routine practice and capture expected differences in VA trajectories by degree of visual loss in the second eye prior to treatment initiation.

Limited data were available to inform the rate of VA loss in untreated eyes immediately following conversion to nAMD. Whilst the EDNA study was able to provide a reasonable estimate of the proportion expected to lose 10 or more letters within 3-6 months of conversion, the tendency to treat prior to significant vision loss resulted in uncertainty around the extrapolation of this input. However, more conservative extrapolations were explored, and the ICER for SD-OCT remained favourable. To ensure the impact of visual loss in the EDNA study eye (second eye) was not underestimated, the second eye was assumed to represent the better seeing eye over the model time horizon. Whilst this will hold true for the majority, VA in the second eye may drop below that of the first eye in some patients. Thus, the model may slightly overestimate the health benefits and cost savings of early detection and treatment. In line with the EDNA study design, the analysis was conducted for a cohort of patients being monitored in UK NHS hospital eye services. Therefore, the costeffectiveness findings do not generalise directly to contexts where monitoring of the second eye occurs in the community. If the superior diagnostic performance of OCT observed in EDNA can be replicated in the community, there is scope for it to offer a cost-effective 
option in this context. However, this would also depend on the comparative costs of the different diagnostic tests when carried out in the community, and a detailed assessment of this was outside the scope of EDNA. Similarly, generalisability outside the UK NHS is uncertain.

To our knowledge this is the first study to assess cost-effectiveness of alternative diagnostic monitoring strategies for $\mathrm{nAMD}$ in the second eye of patients being treated for unilateral nAMD. In a previous health technology assessment, Mowatt et al. reported a high degree of uncertainty regarding the optimal use of SD-OCT in the NAMD monitoring and treatment pathway. ${ }^{28}$ This was in part due to limitations in the evidence base for diagnostic accuracy available at the time. The EDNA study has provided robust evidence for the high diagnostic accuracy of SD-OCT as a monitoring test for the early detection of nAMD in the second eye, and the economic modelling reported here suggests it is likely to offer a cost-effective strategy in this context.

We are aware of one study that has assessed the cost-effectiveness of immediate anti-VEGF treatment in patients with VA better than 70 letters at detection compared to waiting for VA to drop below 70 letters. ${ }^{33}$ Using data from the nAMD UK database on patients with VA above 70 letters at detection, Butt and colleagues estimated the time for VA to a drop below 70 letters without treatment. Their modelling suggested that immediate treatment would maintain better VA and offer a cost-effective use of NHS resources in the short to medium term (2-10 years). Our modelling produced consistent findings but using a lifetime horizon, and including costs associated with severe visual impairment, we found immediate treatment based on FFA confirmed SD-OCT positive findings to offer a potentially cost-saving approach.

The modelling reported here suggests that SD-OCT, compared to other available diagnostic monitoring tests, can lead to substantial reductions in the time to diagnosis and treatment of nAMD in the second eye of patients being monitored and treated for nAMD in their first eye. The early initiation of treatment in the second eye, based on FFA confirmed SD-OCT positive findings, can be expected to maintain better VA and health related quality of life compared to less sensitive monitoring strategies, and may deliver cost-savings in the longrun. 
Our base case analysis reflected NICE diagnostic guidance to use FFA to confirm the diagnosis of nAMD. ${ }^{34}$ Clinical practice might vary towards initiating treatment based on SDOCT results alone. While our modelling suggests it is more cost-effective to first confirm the diagnosis of nAMD using FFA rather than proceeding straight to treatment in all OCT positive cases, it is possible that clinical judgment may be applied in practice to efficiently circumvent the need for FFA in some cases without risking inappropriate overtreatment of false positive patients. Finally, considering the value of using fundus evaluation alongside OCT, our modelling suggests that the additional cost may not be justified given the marginal gain in sensitivity.

\section{Acknowledgments}

The authors wish to Acknowledge the contributions of the following groups and people for their respective roles in the conduct of the EDNA study:

Independent members of the EDNA steering committee: Rupert Bourne (Chair), Anat Loewenstein, Michael Bowen, Yemisi Takwoingi, Felicia Hart, Andrea Rodgers, Michael Warren, Cathy Yelf.

Study team and CHaRT support: Lorna Aucott, Claire Cochran, Fernanda Dias da Silva, Gillian Ferry, Mark Forrest, Pauline Garden, Lorna Henderson, Pamela Jamison, Neil Meharg, Alison McDonald, Samantha Wileman; Zoe Batham, Dianne Dejean; Louise Cotterell, Anne Buckle, Sara Shields and Paula Plant.

Reading centre (Central Angiographic Resource Facility) team: Clare Newell, Karleigh Kelso, Alyson Muldrew, Michelle McGauchey, Vittorio Silvestri, Tunde Peto, Savita Madhusudhan, Konstantinos Balaskas. Philip Earle and Cieran Ennis from the BioBank at Queen's University Belfast.

\section{Staff at each trial site:}

\section{Belfast}

Deirdre Burns, Guiseppe Casalino, Usha Chakravarthy (PI), Rebecca Denham, Lesley Doyle, Karen Gillvray, Katie Graham, Jonathan Keenan, Lisa Kelly, Nuala Jane Lavery, Georgios Mangioris, Orla McNally, Tunde Peto (PI), Louise Scullion, Vittorio Silvestri, Georgina Sterrett, Paul Wright, Graham Young

\section{Bradford}

Helen Devonport, Faruque Ghanchi (PI), Nicci Hawes, Charlotte Hazel, Hayley Higgins, Zeid Madanat, Sarah Moss, Roopa Setty

\section{Bristol}


Monalisa Bora, Claire Buckland, Colin Chu, Julie Cloake, Georgios Farantzos, Eleanor Hiscott, Sameer Hussein, Alice Johns, Danielle Lee, Rebecca Lunn, Stephanie Petrausluas, Adam Ross (PI), Serena Salvatore, Helen Talbot

\section{Cardiff}

Ayad Al-Bermani, Sanjiv Banerjee (PI), Emma Dimond, Helen Hill, Kate Humphreys, Rhianon Reynolds, Pravin Sandanshiv, Chris Tetley, Hayley Westwood, Visith Sidath Wijetilleka, Caroline Young, Tafadzwa Young-Zvandasara

\section{Colchester}

Giles Baggiony-Taylor, Elaine Chinery, Christopher Ellis, Judith Field, Alison Ghosh, Nicola Hopkins (PI), Tasneem Khatib, Jignesh Patel

\section{Edinburgh}

Ali Al-Ani, Ana Maria Armbrecht, Shyamanga Borooah, Marion Brannan, Peter Cackett, Meg Das, Baljean Dhillon (PI), Margaret Frost, Mark Hope, Ash Khan, Margaret McDonald, Douglas Mitchell, Louise Ogilvie

\section{Frimley Park}

Tayaba Akhter, Nadir Ali, Harbhajan Arora, Nadia Azad, Elizabeth Baker, Reynette Baroman, Leena Bhat, Manju Chandran, Maheswari Chekuri, Gloria Crawford, John Deligiannis, Mohamed El-Hefrim, Fernando Esposito, Sarah Gee, Petya Gencheva, Talat Gondal, Harinder Grewal, Jessica Haney, Ali Hassan, Wendy Hockney, Victoria Hodgson, Charlene Humphries, Psiyanta Kakai, Vijay Kakkar, Jaskiran Kaur Sandhu, Radhika Kotecha, Teena Kunnath, Stella Lee, Sally Mathew, Lesley McAllister, Brendan McIlhargey, Jessica McKean, Gail McKenzie, Lorraine McLoughlin, Geeta Menon (PI), Prashant Mistry, Narendran Nair, Karima Nesnas, Lorraine North, Rohina Patel, Ganga Pathinayake, Abigail Raguro, Darryl Ratiram, Rani Retnamma, Deana Robson, Anitha Sethumadhavan, Priyanka Srikanth, Kathryn Walters, Debbie Young, Fani Zacharaki, Louisa Zouita

\section{Gloucester}

Robert Johnston (PI), Peter Scanlon (PI), Fadi Alkherdahji, Jade Ayland, Liz Bristow, Victoria Edgeworth, Helen Fisher, Emily Fletcher, Quresh Mohamed, Rachel Healy, Katerina Ivanova, Seb James, Vanessa Jones, Antonis Kaintatzis, Laura Lodge, Jennifer Mackenzie, Dawn Phillips, Jeffrey Pick, Claire Porter, Bridget Rosser, Karen Townsend

\section{Harrogate}

Bushra Al-Deiri, Tony Burton, Oana-Gabriela Graves, James Featherstone, Theodora Georgouli, Mamta Gupta, Natalie Hollingsworth, Sarah Mackenzie (PI), Karen Martin, Tracy Nixon, Kim Oses-Fred, Eve Panesar, Clare Stemp, Jo Varley, Gavin Walters 


\section{Hillingdon}

Muhammed Aliahmed, Balisee Beruessa, Doris Bilayon, Teresita Bolanos, Richard CheongLeen, Sheena George (PI), Charlene Hamid, Darren Hanumunthasu, Jason Ho, Neo Johnson, Kash Khuttan, Dhakshi Kumar, Ashley Long, Sonal Mehta, Rahila Naureen, Angelos Raytis, Anju Shrestha, Georgios Sotiropoulos, Denise Wheeler, Elizabeth Woodstock

\section{Hull}

Seem Arora, Angela Atkinson, Atiq Babar, Helen Cook, Sally Cooper, Mark Costen, Louise Downey (PI), Kala Gopalakrishnan, Helen Hobman, Krishnappa Madhusudhana, Anish Mani, Christine Mayman, Muhammad Shaikh, Naomi Teal, Yvonne Waudby, Naeem Zaman James Paget University Hospital

Ben Burton (PI), Debbie Busby, Stephanie Cotton, Kelly Evers, Katherine MacKintosh, Helen Nutt, Lucy Palmer, Lesley Parsons, Loretta Poundall, Umair Qidwai, Mya So, Emma Stimpson, Thomas Webber, Celia Whitehouse

\section{Leeds}

Samantha Bird, Frances Cassidy, James Cook, Swetha Devabhakthini, Mohammed Jama, Martin McKibbin (PI), Raj Mukherjee, Mike Stockton, Charmain Tidswell, Alice van Lare,

\section{Leicester}

Mandy Babbington, Kayleigh Brown, Sreekala Burgula, Patrina Christian, Melanie Chrystal, Sue Cockburn, Lee Daines, Theo Empeslidis (PI), Howard Fairey, Andrew Farmer, Konstantina Gorgoli, Vasileios Konidaris, Bhavesh Mistry, Eshmael Palmer, Michelle Rickerby, Lauren Rybicki, Konstantinos Tsaousis

\section{Liverpool}

Julia Baxter, Alina Cordos, Karen Hawkins, Heinrich Heimann (PI), Vivian Ho, Oana Hotu, Samantha Jackson, Robert Jardine, Darina Koneva, Jae Ku, Pauline Lenfestey, Andrea Madden, Savitha Madhusudhan, Ira Mahac, Ian Pearce, Jayne Schumacher, Sandra Taylor

\section{Manchester}

Mohammed Abid, Amy Aldridge, Tariq Aslam (PI), Aaron Bain, Konstantinos Balaskas, Rachel Bambrick, Goncalo Bento, Jay Brown, Ryan Carney, Rosalind Creer, Natalie Fox, Thomas Hamper, Mania Horani, Narcisa Ianopol, Binu John, Emma Linton, Katie McGuiness, Harriet Ndu-Melekwe, Jeremy Parkes, Laura Perry, Raisa Platt, Afeefa Rasheeth, Leanne Richards, Amy Stone (PI), Daniel Todd

\section{Moorfields}

Joynal Abadin, Nadine Abdelgalil, Muna Ali, Minara, Begim, Rawona Berinde, Kanom Bibi, Asma Burale, Dominic Carrington, Cristina Citu, Monica Clemo, Eleanor Connolly, Roxanne 
Crosby-Nwaobi, Diana Dabrickaite, Supeetha David, Jenny Elliot, Sherene Ettienne,

Charlene Formento, Sash Jeetun, Layla Juma, Alexa King, Shamaine King, Tabassum

Master, Aldrich Meneces, Deepthy Menon, April Neville, Luke Nicholson, Andrea

Ogunyemi, Sweta Panchagnula, Namritha Patrao, Panayiotis Panayiotou, Samiul Rahman,

Jayashree Ramu, Nafeesa Reece, Joshua Robinson, Vincent Rocco, Priyansha Sheel, Roy

Schwartz, Anar Shaikh, Sobha Sivaprasad (PI), Hayley Thomas, Emerson Tingco, Marta

Zola

Rugby

Jeanette Allison, Susanne Armitage, Jenny Bhatti, Amritpal Chaggar, Krystal Gale, Jeanette

Houston, Peter James, Charlotte Johnson, Obaid Kousha, Caitlin Lumsden, Marie McCauley, Parimala Nagarajan, Sergio Pagliarini (PI), Linzi Randle, Helen Shawl

\section{Sheffield}

Nachiketa Acharya, Naadir Ansari, Christopher Brand (PI), Stephen Connell, Maria Edwards, Mary Freeman, Helen Pokora, Fahd Quhill, Lydia Reaney, Martin Rhodes, Katherine Wheeler

\section{Southampton}

Hussein Almuhtaseb, Magdalena Ansari, Joanna Ballingall, Mercy Jeyeraj, Joanna Karkorz, Samir Khandhadia, Theodora Koutresi, Andrew Lotery (PI), Georgiana Matei, Marie Nelson, Thea Sass, Amanda Smith, Suresh Thulasidharan, George Tsokolas, Sirli Veetousme, Catrin Watkins, Isabela Wica

\section{Stoke Mandeville}

Judith Abrams, Kavita Aggarwal, Ahmad Ahmado, Tayaba Akhtar, Mandeep Singh Bindra (PI), Nicola Cronbach, Amelia Davidson, Markus Groppe, Shreya Haldar, Christopher King, Katarina Manso, Libby McKerrow, Ruth Penn, Jamil Razzaque, Pavandeep Singh Sandhu, Shafak Toufeeq

\section{Sunderland}

Steve Dodds, Louise Fairlie, Lauren Gardner, Casper Geenan, Maged Habib, Hugh Harris, Ajay Kotagiri (PI), Haifa Madi, Teresa Sandinha (PI), Gemma Sloanes, Jonathan Smith, David Steel, Nicolle Teasdale, Deepali Varma, Jade Ward, Michelle Young, Jill O’Brien Wolverhampton

Bhogal Singh Bhogal, Vina Bhundia, Nick Denyer, Gemma Edwards, Ibtesam Elaraoud, Imogen Hawthorne, Jennifer Howell, Sharon Hughes, Donna Jones, Susan Massey, José Maya, Nirodhini Narendran (PI), Jas Purewal, Habiba Saedon, Sara Simmons, Richard Webb, Diane Whistance-Smith, Yit Chiun Yang 


\section{York}

Archana Airody, Fiona Bailey, Robert Cann, Richard Gale (PI), Srilakshmi Gollapothu, Alison Grice-Holt, Reema Gupta, Richard Hanson, Greg Heath, Gary Lamont, Mike Pringle, Carol Sarginson, Helen Shaw, Sara Stringer, Nicola Topping, Gavin Walters, Joanne Wincup

Competing interests: The Authors report grant funding for the study from the NIHR HTA programme. Dr. Sivaprasad reports grants and personal fees from Novartis, grants from Allergan, grants and personal fees from Roche, grants and personal fees from Boehringer Ingleheim, personal fees from Apellis, personal fees from Oxurion, personal fees from Heidelberg Engineering, personal fees from Optos, grants and personal fees from Bayer, outside the submitted work. Dr. Gale reports grants and personal fees from Novartis, grants and personal fees from Bayer, personal fees from Roche, and personal fees from Almeria / allergan, outside the submitted work. Prof Ramsay is a member of NIHR HTA General Board. Prof. Chakravarthy reports personal fees from Roche, outside the submitted work. Dr. Scotland reports non-financial support from Merck KGaA, outside the submitted work.

Funding: The project was funded by the National Institute for Health Research (NIHR) Health Technology Assessment Programme (grant number: 12/142/07) and will be published in full in Health Technology Assessment. The funder was not involved in the study design; in the collection, analysis and interpretation of the data; in the writing of the report; and in the decision to submit the paper for publication. The Health Services Research Unit (HSRU) and the Health Economics Research Unit (HERU) are core funded by the Chief Scientist Office of the Scottish Government Health and Social Care Directorate (HSRU/2021-2024, HERU/2021-2024).

\section{Ethics:}

The Office for Research Ethics Committees in Northern Ireland (ORECNI) reviewed and approved this study (14/NI/1120), and the study was prospectively registered on ISRCTN48855678. Informed consent was obtained for all patients and the study followed the Declaration of Helsinki. 


\section{References}

1. Royal College of Ophthalmologists. Age-related macular degeneration: Guidelines for management [document on the internet]. http://www.rcophth.ac.uk/wpcontent/uploads/2014/12/2013-SCI-318-RCOphth-AMD-Guidelines-Sept-2013-FINAL2.pdf. Updated 2013. Accessed June, 2020.

2. Bakri SJ, Thorne JE, Ho AC, et al. Safety and efficacy of anti-vascular endothelial growth factor therapies for neovascular age-related macular degeneration: A report by the american academy of ophthalmology. Ophthalmol. 2019;126(1):55-63.

3. Mehta H, Tufail A, Daien V, et al. Real-world outcomes in patients with neovascular agerelated macular degeneration treated with intravitreal vascular endothelial growth factor inhibitors. Prog Retin Eye Res. 2018;65:127-146.

4. Evans RN, Reeves BC, Phillips D, et al. Long-term visual outcomes after release from protocol in patients who participated in the inhibition of VEGF in age-related choroidal neovascularisation (IVAN) trial. Ophthalmology. 2020;127(9):1191-1200.

5. Karnon J, Czoski-Murray C, Smith K, et al. A preliminary model-based assessment of the cost-utility of a screening programme for early age-related macular degeneration. Health Technol Assess. 2008;12(27).

6. Zarranz-Ventura J, Liew G, Johnston RL, et al. The neovascular age-related macular degeneration database: Report 2: Incidence, management, and visual outcomes of second treated eyes. Ophthalmol. 2014;121(10):1966-1975. 
7. Chakravarthy U (Chief Investigator). EDNA: Early detection of neovascular age-related macular degeneration (AMD) PROTOCOL. . 2018; Version 4.0.

https://fundingawards.nihr.ac.uk/award/12/142/07

8. Gale R (Chief Investigator). FASBAT study. observing fibrosis, macular atrophy and sub retinal highly reflective material - before and after intervention with anti-VEGF treatment: An extension to the EDNA study. study protocol. . 2018; Version 7.0.

9. Lee AY, Lee CS, Butt T, et al. UK AMD EMR users group report V: Benefits of initiating ranibizumab therapy for neovascular AMD in eyes with vision better than $6 / 12 . \mathrm{Br} J$ Ophthalmol. 2015;99(8):1045-1050.

10. Chakravarthy U, Harding SP, Rogers CA, et al. Alternative treatments to inhibit VEGF in age-related choroidal neovascularisation: 2-year findings of the IVAN randomised controlled trial. Lancet. 2013;382(9900):1258-1267.

11. Chakravarthy U, Harding SP, Rogers CA, et al. A randomised controlled trial to assess the clinical effectiveness and cost-effectiveness of alternative treatments to inhibit VEGF in age-related choroidal neovascularisation (IVAN). Health Technol Assess. 2015;19(78):1-298.

12. Claxton L, Hodgson R, Taylor M, Malcolm B, Pulikottil Jacob R. Simulation modelling in ophthalmology: Application to cost effectiveness of ranibizumab and aflibercept for the treatment of wet age-related macular degeneration in the united kingdom.

Pharmacoeconomics. 2017;35(2):237-248.

13. Chandra S, Arpa C, Menon D, et al. Ten-year outcomes of antivascular endothelial growth factor therapy in neovascular age-related macular degeneration. Eye. 2020;doi: 10.1038/s41433-020-0764-9. 
14. Tosh J, Brazier J, Evans P, Longworth L. A review of generic preference-based measures of health-related quality of life in visual disorders. Value Health. 2012;15(1):118-127.

15. Espallargues M, Czoski-Murray CJ, Bansback NJ, et al. The impact of age-related macular degeneration on health status utility values. Invest Ophthalmol Vis Sci. 2005;46(11):4016-4023.

16. Butt T, Dunbar HMP, Morris S, Orr S, Rubin GS. Patient and public preferences for health states associated with AMD. Optometry Vision Sci. 2013;90(8):855-860.

17. Butt T, Crossland MD, West P, Orr SW, Rubin GS. Simulation contact lenses for AMD health state utility values in NICE appraisals: A different reality. $\mathrm{Br}$ J Ophthalmol. 2015;99(4):540-544.

18. Butt T, Tufail A, Rubin G. Health state utility values for age-related macular degeneration: Review and advice. Applied Health Economics \& Health Policy. 2017;15(1):23-32.

19. Brown GC, Sharma S, Brown MM, Kistler J. Utility values and age-related macular degeneration. Arch Ophthalmol. 2000;118(1):47-51.

20. Dixon P, Dakin H, Wordsworth S. Generic and disease-specific estimates of quality of life in macular degeneration: Mapping the MacDQoL onto the EQ-5D-3L. Qual Life Res. 2016;25(4):935-945.

21. Hodgson R, Reason T, Trueman D, et al. Challenges associated with estimating utility in wet age-related macular degeneration: A novel regression analysis to capture the bilateral nature of the disease. Adv Ther. 2017;34(10):2360-2370. 
22. Czoski-Murray C, Carlton J, Brazier J, Young T, Papo NL, Kang HK. Valuing conditionspecific health states using simulation contact lenses. Value in Health. 2009;12(5):793-799.

23. Longworth L, Yang Y, Young T, et al. Use of generic and condition-specific measures of health-related quality of life in NICE decision-making: A systematic review, statistical modelling and survey. Health Technol Assess. 2014;18(9):1-224.

24. National Institute for Health and Care Excellence. Ranibizumab and pegaptanib for the treatment of age-related macular degeneration [TA155].

https://www.nice.org.uk/guidance/ta155. Updated 2012. Accessed July, 2020.

25. National Institute for Health and Care Excellence. Aflibercept solution for injection for treating wet age-related macular degeneration [TA294].

https://www.nice.org.uk/guidance/ta294. Updated 2014. Accessed July, 2020.

26. Curtis L, Burns A. Unit costs of health and social care. https://www.pssru.ac.uk/projectpages/unit-costs/unit-costs-2019/. Updated 2019. Accessed March, 2020.

27. Department of Health and Social Care. 2018/19 national cost collection data. https://improvement.nhs.uk/resources/national-cost-collection/. Updated 2019. Accessed July, 2020.

28. Mowatt G, Hernandez R, Castillo M, et al. Optical coherence tomography for the diagnosis, monitoring and guiding of treatment for neovascular age-related macular degeneration: A systematic review and economic evaluation. Health Technol Assess. 2014;18(69):1-254.

29. Royal Pharmaceutical Society. British national formulary [online version]. https://www.medicinescomplete.com/about/. Updated 2020. Accessed February, 2020. 
30. Dakin HA, Wordsworth S, Rogers CA, et al. Cost-effectiveness of ranibizumab and bevacizumab for age-related macular degeneration: 2-year findings from the IVAN randomised trial. BMJ Open. 2014;4(7):e005094.

31. National Institute for Health and Care Excellence. Guide to the methods of technology appraisal 2013. https://www.nice.org.uk/process/pmg9/chapter/foreword. Updated 2013. Accessed June, 2020.

32. Briggs AD, Wolstenholme J, Blakely T, Scarborough P. Choosing an epidemiological model structure for the economic evaluation of non-communicable disease public health interventions. Popul Health Metr. 2016;14:17-016-0085-1. eCollection 2016.

33. Butt T, Lee A, Lee C, Tufail A, UK AMD EMR Study Group. The cost-effectiveness of initiating ranibizumab therapy in eyes with neovascular AMD with good vision: An economic model using real-world outcomes. BMJ Open. 2015;5(5):e006535.

34. National Institute for Health and Care Excellence. Age-related macular degeneration [NG82]. https://www.nice.org.uk/guidance/ng82. Updated 2018. Accessed July, 2020. 


\section{Figures and Tables (Main text)}

\section{List of Figures}

Figure 1 Simplified schematic of the model structure

Notes: VA (visual acuity); TN (true negative); FN (false negative); TP (true positive); FFA (fluorescein angiography); Ref (reference standard). Whether or not FFA would be triggered by all positive test results in standard practice is questionable and alternative assumptions are explored.

Figure 2 Cost-effectiveness acceptability curve

\section{List of Tables}

Table 1 Diagnostic accuracy estimates applied in the economic model

Table2 Base case cost-effectiveness results

Table 3 Model output: time lags from conversion to detection and 1st treatment, and visual acuity at first treatment

Table 4 Cost-effectiveness results including the combination of OCT and fundus evaluation

\section{Supplementary Tables and Figures}

\section{List of supplementary Figures}

Supplementary Figure 1 Kaplan-Maier plot of time to conversion overlaid with fitted parametric survival curves

Supplementary Figure 2 Extrapolated time to losing 10 or more and 30 or more letters from the point of conversion

Supplementary Figure 3 Modelled post-treatment visual acuity trajectories of patients by time since treatment initiation (EDNA model)

Note: with application of a VA cap in the model, there is a downward pressure on VA change between months 3 to 24 , which slightly overestimates expected VA deterioration during this time-period compared to the IVAN trial. 


\section{List of supplementary Tables}

Supplementary Table 1 VA change for treated individuals from treatment initiation to 24 months

Supplementary Table 2 Probabilities of treatment discontinuation and treatment reinitiation

Supplementary Table 3 Health state utility inputs

Supplementary Table 4 Marginal testing costs applied in the model

Supplementary Table 5 Monitoring and treatment frequency after conversion to nAMD

Supplementary Table 6 Unit costs for monitoring and treatment following conversion to nAMD

Supplementary Table 7 Details of scenario analyses carried out

Supplementary Table 8 Break down of costs for the base case analysis

Supplementary Table 9 Probabilistic cost-effectiveness results

Supplementary Table 10 Cost-effectiveness scenario analyses 
Supplementary Table 1 VA change for treated individuals from treatment initiation to 24 months

\begin{tabular}{|l|l|l|}
\hline Variable & $\begin{array}{l}\text { Point estimate } \\
\text { (SD) }\end{array}$ & Source \\
\hline $\begin{array}{l}\text { Monthly VA change (months 1- } \\
\text { 3) for eyes with VA loss } \geq 10 \\
\text { letters }\end{array}$ & $2.1567(2.89)$ & $\begin{array}{l}\text { Chakravarthy et al., } \\
\text { Claxton et al., 10,12 } \\
\text { EDNA post-conversion data }\end{array}$ \\
\hline $\begin{array}{l}\text { Monthly VA change (months 3 } \\
-12) \text { for eyes with VA loss } \geq 10 \\
\text { letters. }\end{array}$ & $0.00(2.25)$ & $\begin{array}{l}\text { Chakravarthy et al., } \\
\text { Claxton et al., 10,12 }\end{array}$ \\
\hline $\begin{array}{l}\text { Monthly VA change } \\
\text { (months 13-24) for eyes with } \\
\text { VA loss } \geq 10 \text { letters }\end{array}$ & $-0.0917(2.17)$ & $\begin{array}{l}\text { Chakravarthy et al., } \\
\text { Claxton et al., 10,12 }\end{array}$ \\
\hline
\end{tabular}


Supplementary Table 2 Probabilities of treatment discontinuation and treatment reinitiation

\begin{tabular}{|c|c|c|}
\hline Variable & $\begin{array}{l}\text { Estimated } \\
\text { probability }(\mathrm{SE})^{\mathrm{a}}\end{array}$ & Source \\
\hline $\begin{array}{l}\text { Monthly probability of treatment } \\
\text { discontinuation by VA at } 24 \text { months } \\
\text { post-treatment initiation }\end{array}$ & & Evans et al. $2020^{4}$ \\
\hline$\geq 68$ & $0.0091(0.001)$ & \\
\hline $53-67$ & $0.0143(0.002)$ & \\
\hline $38-52^{b}$ & $0.0095(0.003)$ & \\
\hline$\leq 37$ & $0.0257(0.007)$ & \\
\hline Overall & $0.0174(0.001)$ & \\
\hline Average of 38 to $\geq 68$ & $0.0110(0.002)$ & \\
\hline $\begin{array}{l}\text { Annual probability of re-initiating } \\
\text { treatment following } 12 \text { months stable }\end{array}$ & & $\begin{array}{l}\text { Chandra et al. } 2020 ;{ }^{13} \\
\text { Personal communication, } \\
\text { Sohba Sivaprasad, March } \\
2020 \text {. }\end{array}$ \\
\hline Year 1 & $0.246(0.038)$ & \\
\hline Year 2 onwards & $0.106(0.038)$ & \\
\hline
\end{tabular}

${ }^{a}$ Point estimates and standard errors calculated by the authors from the reported data 
Supplementary Table 3 Health state utility inputs

\begin{tabular}{|l|c|c|}
\hline Utility parameters & Mean & Standard error \\
\hline Constant (baseline) & 0.86 & 0.068 \\
\hline $\begin{array}{l}\text { Decrement per unit } \\
\text { increase in VA } \\
\text { LogMAR }\end{array}$ & -0.368 & 0.046 \\
\hline $\begin{array}{l}\text { Decrement per one } \\
\text { year increase in age }\end{array}$ & -0.001 & 0.002 \\
\hline
\end{tabular}

Source, Czoski-Murray et al. ${ }^{22}$ 
Supplementary Table 4 Testing costs applied in the model

\begin{tabular}{|c|c|c|c|c|c|c|c|}
\hline & \multicolumn{6}{|c|}{ Index test modality } \\
\hline & & \multirow{2}{*}{$\begin{array}{c}\text { OCT } \\
(\mathfrak{f})\end{array}$} & \multicolumn{2}{|c|}{ Fundus clinical evaluation } & \multirow[t]{2}{*}{ Amsler (£) } & \multirow{2}{*}{$\begin{array}{c}\text { Self- } \\
\text { reported } \\
\text { vision }(\mathfrak{f})\end{array}$} & \multirow{2}{*}{$\begin{array}{l}\text { VA } \\
(\mathfrak{E})\end{array}$} \\
\hline & & & Slit lamp (£) & $\begin{array}{c}\text { Photography } \\
(\mathfrak{f})\end{array}$ & & & \\
\hline \multirow{4}{*}{$\begin{array}{l}\text { EDNA } \\
\text { study } \\
\text { eye } \\
\text { (second } \\
\text { eye) }\end{array}$} & Mean & 10.68 & 10.64 & 11.79 & 6.13 & 7.08 & 8.15 \\
\hline & St. dev & 5.19 & 6.32 & 7.11 & 3.05 & 6.68 & 6.32 \\
\hline & Median & 9.71 & 9.91 & 10.04 & 4.83 & 5.05 & 6.26 \\
\hline & IQR & 6.38 & 6.56 & 10.60 & 3.21 & 3.57 & 5.36 \\
\hline \multirow{4}{*}{$\begin{array}{l}\text { First eye } \\
\text { (nAMD } \\
\text { at } \\
\text { baseline) }\end{array}$} & Mean & 19.45 & 18.44 & 13.70 & 6.88 & 8.07 & 10.23 \\
\hline & St. dev & 10.14 & 8.85 & 7.33 & 2.92 & 7.35 & 6.50 \\
\hline & Median & 17.83 & 20.24 & 12.11 & 7.10 & 5.33 & 7.34 \\
\hline & IQR & 11.76 & 13.23 & 9.72 & 3.40 & 4.80 & 6.21 \\
\hline \multirow[t]{4}{*}{ Total } & Mean & 30.13 & 30.79 & 25.48 & 13.01 & 15.14 & 18.38 \\
\hline & St. dev & 14.50 & 10.72 & 13.18 & 5.85 & 13.73 & 12.16 \\
\hline & Median & 29.12 & 31.58 & 22.15 & 12.89 & 10.82 & 13.68 \\
\hline & IQR & 16.47 & 11.58 & 16.97 & 6.14 & 8.82 & 5.36 \\
\hline
\end{tabular}


Supplementary Table 5 Monitoring and treatment frequency after conversion to $\mathrm{nAMD}$

\begin{tabular}{|l|c|c|c|c|}
\hline \multicolumn{2}{|l|}{ Ranibizumab } & \multicolumn{2}{l|}{ Aflibercept } \\
\hline & $\begin{array}{c}\text { Treatment visits } \\
\text { per year } \\
\text { Mean (SE) }\end{array}$ & $\begin{array}{c}\text { Monitoring visits } \\
\text { per year } \\
\text { Mean (SE) }\end{array}$ & $\begin{array}{c}\text { Treatment visits } \\
\text { per year } \\
\text { Mean (SE) }\end{array}$ & $\begin{array}{c}\text { Monitoring visits } \\
\text { per year } \\
\text { Mean (SE) }\end{array}$ \\
\hline Year 1 & $10(0.233)$ & $12^{\mathrm{c}}$ & $7(0.35)$ & $7(0.35)$ \\
\hline Year 2 & $8(0.233)$ & $12^{\mathrm{c}}$ & $6(0.3)$ & $6(0.3)$ \\
\hline Year 3+ & $4(0.277)$ & $9(0.231)$ & $4(0.2)$ & $6(0.3)$ \\
\hline
\end{tabular}

Notes: SE, standard error; a, standard errors approximated from reported medians and inter-quartile ranges; $b$, standard errors assumed as $5 \%$ of the mean; c, applied deterministically. The base case analysis assumed a drug treatment distribution in line with the observed distribution in patients who commenced treatment in their EDNA study eye; aflibercept (68.7\%), ranibizumab (22.3\%), and bevacizumab (9\%). 
Supplementary Table 6 Unit costs for monitoring and treatment following conversion to nAMD

\begin{tabular}{|c|c|c|c|}
\hline Resource & Unit costs & Source & Notes \\
\hline $\begin{array}{l}\text { Ophthalmology } \\
\text { outpatient visit }\end{array}$ & $£ 95$ & $\begin{array}{l}\text { National Cost } \\
\text { Collection } \\
2018-19^{27}\end{array}$ & $\begin{array}{l}\text { Code } 130 \text { Outpatient consultant led } \\
\text { appointment in ophthalmology }\end{array}$ \\
\hline $\begin{array}{l}\text { Fluorescein angiography } \\
\text { (FFA) }\end{array}$ & $£ 145$ & $\begin{array}{l}\text { National Cost } \\
\text { Collection } \\
2018-19^{27}\end{array}$ & $\begin{array}{l}\text { BZ86B Outpatient intermediate } \\
\text { vitreous retinal procedures }\end{array}$ \\
\hline $\begin{array}{l}\text { Administration of anti- } \\
\text { VEGF injection }\end{array}$ & $£ 145$ & $\begin{array}{l}\text { National Cost } \\
\text { Collection } \\
2018-19^{27}\end{array}$ & $\begin{array}{l}\text { BZ86B Outpatient intermediate } \\
\text { vitreous retinal procedures }\end{array}$ \\
\hline $\begin{array}{l}\text { Ranibizumab (Lucentis) } \\
\text { injection }\end{array}$ & $£ 551$ & BNF, $2019^{29}$ & $\begin{array}{l}1.65 \mathrm{mg} / 0.165 \mathrm{ml} \text { solution for } \\
\text { injection pre-filled syringes } \\
\text { (Novartis Pharmaceuticals UK Ltd) }\end{array}$ \\
\hline $\begin{array}{l}\text { Aflibercept (Eylea } \\
\text { injection) }\end{array}$ & $£ 816$ & $\mathrm{BNF}, 2019^{29}$ & $\begin{array}{l}2 \mathrm{mg} / 50 \text { microlitres solution for } \\
\text { injection vials (Bayer Plc) }\end{array}$ \\
\hline $\begin{array}{l}\text { Bevacizumab (Avastin } \\
\text { injection) }\end{array}$ & $£ 49$ & $\begin{array}{l}\text { Dakin et al., } \\
2014^{30}\end{array}$ & $1.25 \mathrm{mg}$ per injection \\
\hline $\begin{array}{l}\text { Cost of blindness } \\
\text { (Health service } \\
\text { perspective) }\end{array}$ & $\begin{array}{l}£ 562.41 \text { per } \\
\text { month in year } 1 \\
£ 541.73 \text { per } \\
\text { month from year } \\
2 \text { onwards }\end{array}$ & $\begin{array}{l}\text { Mowatt, } \\
2014^{28}\end{array}$ & $\begin{array}{l}\text { Cost per month for } \mathrm{VA}<35 \\
\text { ETDRS letters }\end{array}$ \\
\hline
\end{tabular}




\section{Supplementary Table 7 Details of scenario analyses carried out}

\begin{tabular}{|c|c|}
\hline Scenario & Description \\
\hline 1. & $\begin{array}{l}\text { The Weibull distribution applied to model time to conversion to nAMD, giving an } \\
\text { increasing hazard of conversion over time. }\end{array}$ \\
\hline 2. & $\begin{array}{l}\text { The lognormal distribution applied to model time to conversion to nAMD, giving a } \\
\text { decreasing hazard of conversion over time. }\end{array}$ \\
\hline 3. & $\begin{array}{l}\text { The Lognormal distribution applied to model time from conversion to nAMD to } \\
\text { significant vision loss ( } \geq 10 \text { letters) }\end{array}$ \\
\hline 4. & $\begin{array}{l}\text { The generalised gamma distribution applied to model time from conversion to } \\
\text { nAMD to significant vision loss ( } \geq 10 \text { letters) }\end{array}$ \\
\hline 5. & $\begin{array}{l}\text { Pre-treatment VA loss conditional on dropping } 10-29 \text { and } \geq 30 \text { letters assumed to be } \\
\text { skewed towards the lower end of the VA loss ranges; mean }=12 \text { and mean } 32 \text { letters, } \\
\text { respectively }\end{array}$ \\
\hline 6. & $\begin{array}{l}\text { A reduced longer-term rate of post-treatment VA decline applied; } 3.1 \text { letters per year } \\
\text { in line with the average rate of decline estimated for younger patients (aged 70) in } \\
\text { the IVAN long-term follow-up study. }\end{array}$ \\
\hline 7. & $\begin{array}{l}\text { A reduced longer-term rate of post-treatment VA decline applied; } 2 \text { letters per year } \\
\text { in line with the average rate of decline estimated for younger patients (aged 60) in } \\
\text { the IVAN long-term follow-up study }\end{array}$ \\
\hline 8. & $\begin{array}{l}\text { Distribution for long-term post-treatment rate of VA loss per year assumed to be } \\
\text { right skewed and constrained by } 0 \text {; gamma distribution with mean=4.3, standard } \\
\text { deviation }=7 \text {. }\end{array}$ \\
\hline 9. & $\begin{array}{l}\text { A reduced rate of treatment discontinuation for stable vision applied (0.0092), based } \\
\text { on data from Chandra et al. (applied independent of VA outcome at } 24 \text { months post } \\
\text { treatment) }\end{array}$ \\
\hline 10. & $\begin{array}{l}\text { Removal of treatment discontinuation for stable vision (an extreme scenario to assess } \\
\text { the impact of this uncertain parameter). }\end{array}$ \\
\hline 11. & $\begin{array}{l}\text { An increased rate of treatment re-initiation (approximately } 2.9 \% \text { per month) } \\
\text { following discontinuation for stable disease, in line with data reported by } \\
\text { Madhusudhana et al (2016).83 }\end{array}$ \\
\hline 12. & $\begin{array}{l}100 \% \text { test sensitivity applied for all tests at the subsequent monitoring visit for those } \\
\text { who lose } 15-29 \text { letters due to nAMD. }\end{array}$ \\
\hline 13. & Removal of excess mortality associated with visual impairment. \\
\hline 14. & Removal of costs of blindness \\
\hline 15. & $\begin{array}{l}\text { Wait to treat policy, which assumes VA must drop below the threshold specified for } \\
\text { ranibizumab and aflibercept in NICE TA guidance ( } \leq 70 \text { letters). }\end{array}$ \\
\hline
\end{tabular}




\begin{tabular}{|l|l|}
\hline 16. & $\begin{array}{l}\text { Treatment instigated following OCT positive findings, without confirmation with } \\
\text { FFA - this assumes that any patient receiving a false positive OCT result incurs } 12 \\
\text { months' worth of anti-VEGF treatment inappropriately, before being identified as } \\
\text { morphologically unchanged and treatment withdrawn. }\end{array}$ \\
\hline 17. & $\begin{array}{l}\text { Increased test monitoring costs as per the increased overhead scenario outlined in the } \\
\text { health economics appendix. }\end{array}$ \\
\hline 18. & $\begin{array}{l}\text { Assume no further monitoring for conversion from } 5 \text { years, based on the probability } \\
\text { that a majority of first eyes may be discharged from active treatment by this time } \\
\text { point. }\end{array}$ \\
\hline
\end{tabular}


Supplementary Table 8 Break down of costs for the base case analysis

\begin{tabular}{|l|c|c|c|c|c|}
\hline & Total & $\begin{array}{c}\text { Monitoring } \\
\text { pre- } \\
\text { diagnosis }\end{array}$ & $\begin{array}{c}\text { Monitoring } \\
\text { post- } \\
\text { diagnosis }\end{array}$ & Treatment & Blindness \\
\hline OCT & 19,406 & 2,573 & 2,576 & 10,966 & 3,291 \\
\hline $\begin{array}{l}\text { Fundus clinical } \\
\text { evaluation }\end{array}$ & 19,649 & 2,588 & 2,506 & 10,685 & 3,870 \\
\hline Amsler & 19,751 & 2,502 & 2,426 & 10,362 & 4,461 \\
\hline Self-reported vision & 20,198 & 2,565 & 2,261 & 9,700 & 5,672 \\
\hline Visual acuity & 20,444 & 2,644 & 2,226 & 9,562 & 6,013 \\
\hline
\end{tabular}

Table 9 Probabilistic cost-effectiveness results

\begin{tabular}{|l|c|c|c|c|c|}
\hline Monitoring Strategy & $\begin{array}{c}\text { Cost } \\
(\mathfrak{f})\end{array}$ & $\begin{array}{c}\text { Incremental } \\
\text { Cost }(\mathfrak{f})\end{array}$ & QALYs & $\begin{array}{c}\text { Incremental } \\
\text { QALYs }\end{array}$ & ICER (£) \\
\hline OCT & 19,660 & & 5.842 & & \\
\hline $\begin{array}{l}\text { Fundus clinical } \\
\text { evaluation }\end{array}$ & 19,900 & 240 & 5.796 & -0.046 & Dominated \\
\hline Amsler & 20,069 & 169 & 5.744 & -0.098 & Dominated \\
\hline Self-reported vision & 20,659 & 590 & 5.644 & -0.198 & Dominated \\
\hline Visual acuity & 20,900 & 242 & 5.615 & -0.227 & Dominated \\
\hline
\end{tabular}




\section{Supplementary Table 10 Results of cost-effectiveness scenario analyses}

\begin{tabular}{|c|c|c|c|c|c|}
\hline Strategy & $\operatorname{Cost}(\mathfrak{f})$ & $\begin{array}{c}\text { Incremental } \\
\text { Costs }(\mathfrak{E})\end{array}$ & QALYs & $\begin{array}{c}\text { Incremental } \\
\text { QALYs }\end{array}$ & $\operatorname{ICER}(\mathfrak{f})$ \\
\hline \multicolumn{6}{|c|}{$\begin{array}{l}\text { 1. Weibull distribution applied to model time to conversion to nAMD, giving an increasing hazard } \\
\text { of conversion over time }\end{array}$} \\
\hline OCT & 19,909 & & 5.806 & & \\
\hline Fundus clinical evaluation & 20,178 & 269 & 5.761 & -0.046 & $-5,898 * *$ \\
\hline Amsler & 20,290 & 381 & 5.709 & -0.098 & $-3,892 * *$ \\
\hline Self-reported vision & 20,754 & 845 & 5.601 & -0.205 & $-4,123 * *$ \\
\hline Visual acuity & 20,993 & 1,084 & 5.572 & -0.235 & $-4,617 * *$ \\
\hline \multicolumn{6}{|c|}{$\begin{array}{l}\text { 2. LogNormal distribution applied to model time to conversion to nAMD, giving a decreasing } \\
\text { hazard of conversion over time }\end{array}$} \\
\hline OCT & 17,288 & & 5.926 & & \\
\hline Fundus clinical evaluation & 17,501 & 212 & 5.888 & -0.037 & $-5,687 * *$ \\
\hline Amsler & 17,550 & 261 & 5.843 & -0.083 & $-3,163 * *$ \\
\hline Self-reported vision & 17,969 & 681 & 5.748 & -0.178 & $-3,826^{* *}$ \\
\hline Visual acuity & 18,219 & 931 & 5.721 & -0.205 & $-4,545^{* *}$ \\
\hline \multicolumn{6}{|c|}{$\begin{array}{l}\text { 3. Lognormal distribution applied to model time from conversion to nAMD to losing } 10 \text { or more } \\
\text { letters without treatment. }\end{array}$} \\
\hline OCT & 19,616 & & 5.806 & & \\
\hline Fundus clinical evaluation & 19,854 & 238 & 5.765 & -0.041 & $-5,773 * *$ \\
\hline Amsler & 19,899 & 283 & 5.723 & -0.083 & $-3,406^{* *}$ \\
\hline Self-reported vision & 20,049 & 433 & 5.644 & -0.161 & $-2,679 * *$ \\
\hline Visual acuity & 20,112 & 496 & 5.620 & -0.186 & $-2,672 * *$ \\
\hline \multicolumn{6}{|c|}{$\begin{array}{l}\text { 4. Generalised gamma distribution applied to model time from conversion to nAMD to losing } 10 \text { or } \\
\text { more letters without treatment. }\end{array}$} \\
\hline Visual acuity & 18,853 & & 5.688 & & \\
\hline Self-reported vision & 19,311 & 458 & 5.690 & 0.002 & $293,816^{*}$ \\
\hline OCT & 19,760 & 907 & 5.788 & 0.100 & 9,040 \\
\hline Amsler & 19,833 & 73 & 5.728 & -0.060 & $-1,229 * *$ \\
\hline Fundus clinical evaluation & 19,912 & 153 & 5.756 & -0.032 & $-4,745 * *$ \\
\hline \multicolumn{6}{|c|}{$\begin{array}{l}\text { 5. Letter losses conditional on dropping } 10-29 \text { and } \geq 30 \text { letters assumed to be skewed towards the } \\
\text { highest end of the range; mean }=12 \text { and mean } 32 \text { respectively }\end{array}$} \\
\hline Self-reported vision & 18,728 & & 5.780 & & \\
\hline Amsler & 18,755 & 27 & 5.836 & 0.057 & 470 \\
\hline Visual acuity & 18,831 & 76 & 5.763 & -0.073 & $-1,037 * *$ \\
\hline Fundus clinical evaluation & 18,867 & 112 & 5.861 & 0.025 & $4,478^{*}$ \\
\hline OCT & 18,878 & 123 & 5.883 & 0.046 & 2,655 \\
\hline \multicolumn{6}{|c|}{$\begin{array}{l}\text { 6. Reduced long-term rate of post treatment VA decline from } 4.3 \text { letters per year to } 3.1 \text { letters per } \\
\text { year }\end{array}$} \\
\hline OCT & 18,592 & & 5.925 & & \\
\hline Fundus clinical evaluation & 18,839 & 247 & 5.878 & -0.047 & $-5,237 * *$ \\
\hline Amsler & 18,975 & 382 & 5.822 & -0.102 & $-3,733 * *$ \\
\hline Self-reported vision & 19,455 & 863 & 5.703 & -0.221 & $-3,897 * *$ \\
\hline Visual acuity & 19,690 & 1,097 & 5.671 & -0.253 & $-4,331 * *$ \\
\hline
\end{tabular}




\begin{tabular}{|c|c|c|c|c|c|}
\hline OCT & 17,987 & & 6.016 & & \\
\hline Fundus clinical evaluation & 18,193 & 206 & 5.965 & -0.051 & $-4,067 * *$ \\
\hline Amsler & 18,289 & 302 & 5.906 & -0.110 & $-2,748 * *$ \\
\hline Self-reported vision & 18,712 & 725 & 5.778 & -0.238 & $-3,045^{* *}$ \\
\hline Visual acuity & 18,915 & 929 & 5.744 & -0.272 & $-3,415 * *$ \\
\hline \multicolumn{6}{|c|}{$\begin{array}{l}\text { 8. Distribution for long-term post-treatment rate of letter loss per year assumed to right skewed and } \\
\text { constrained by } 0 \text {; gamma distribution with mean }=4.3 \text {, standard deviation }=7\end{array}$} \\
\hline OCT & 19,132 & & 5.954 & & \\
\hline Amsler & 19,182 & 51 & 5.839 & -0.115 & $-441 * *$ \\
\hline Fundus clinical evaluation & 19,184 & 52 & 5.899 & -0.055 & $-944 * *$ \\
\hline Self-reported vision & 19,464 & 333 & 5.729 & -0.226 & $-1,475^{* *}$ \\
\hline Visual acuity & 19,614 & 482 & 5.696 & -0.258 & $-1,870 * *$ \\
\hline \multicolumn{6}{|c|}{$\begin{array}{l}\text { 9. Reduced rate of treatment discontinuation for stable vision to } 0.0092 \text { based on data from Chandra } \\
\text { et al. }\end{array}$} \\
\hline OCT & 19,957 & & 5.816 & & \\
\hline Fundus clinical evaluation & 20,175 & 218 & 5.772 & -0.043 & $-5,028 * *$ \\
\hline Amsler & 20,265 & 307 & 5.722 & -0.094 & $-3,284 * *$ \\
\hline Self-reported vision & 20,699 & 741 & 5.619 & -0.197 & $-3,765 * *$ \\
\hline Visual acuity & 20,934 & 976 & 5.588 & -0.227 & $-4,292 * *$ \\
\hline \multicolumn{6}{|c|}{ 10. No treatment discontinuation for stable vision } \\
\hline OCT & 23,854 & & 5.723 & & \\
\hline Amsler & 23,857 & 3 & 5.640 & -0.082 & $-36^{* *}$ \\
\hline Fundus clinical evaluation & 23,941 & 87 & 5.686 & -0.037 & $-2,373 * *$ \\
\hline Self-reported vision & 23,978 & 124 & 5.549 & -0.173 & $-715^{* *}$ \\
\hline Visual acuity & 24,124 & 269 & 5.524 & -0.199 & $-1,356 * *$ \\
\hline \multicolumn{6}{|c|}{ 11. Increased rate of re-initiation of therapy following discontinuation with stable vision. } \\
\hline OCT & 20,457 & & 5.792 & & \\
\hline Fundus clinical evaluation & 20,664 & 207 & 5.751 & -0.042 & $-4,973 * *$ \\
\hline Amsler & 20,725 & 268 & 5.703 & -0.090 & $-2,989 * *$ \\
\hline Self-reported vision & 21,104 & 647 & 5.602 & -0.191 & $-3,390 * *$ \\
\hline Visual acuity & 21,329 & 872 & 5.574 & -0.219 & $-3,990 * *$ \\
\hline \multicolumn{6}{|c|}{$\begin{array}{l}\text { 12. } 100 \% \text { test sensitivity applied for all tests at the next monitoring visit for those who lose } 15-30 \\
\text { letters due to nAMD }\end{array}$} \\
\hline OCT & 19,405 & & 5.830 & & \\
\hline Fundus clinical evaluation & 19,640 & 236 & 5.786 & -0.044 & $-5,359 * *$ \\
\hline Amsler & 19,740 & 336 & 5.736 & -0.095 & $-3,545^{* *}$ \\
\hline Self-reported vision & 20,189 & 784 & 5.630 & -0.200 & $-3,913 * *$ \\
\hline Visual acuity & 20,442 & 1,037 & 5.600 & -0.231 & $-4,497 * *$ \\
\hline \multicolumn{6}{|c|}{ 13. No excess mortality due to VA loss } \\
\hline OCT & 20,234 & & 5.931 & & \\
\hline Fundus clinical evaluation & 20,531 & 297 & 5.887 & -0.044 & $-6,716 * *$ \\
\hline Amsler & 20,692 & 458 & 5.837 & -0.094 & $-4,876^{* *}$ \\
\hline Self-reported vision & 21,259 & 1,025 & 5.734 & -0.197 & $-5,195 * *$ \\
\hline Visual acuity & 21,542 & 1,308 & 5.705 & -0.227 & $-5,774 * *$ \\
\hline
\end{tabular}




\begin{tabular}{|l|c|c|c|c|c|}
\hline Visual acuity & 14,432 & & 5.600 & & \\
\hline Self-reported vision & 14,527 & 95 & 5.630 & 0.030 & 3,144 \\
\hline Amsler & 15,290 & 763 & 5.736 & 0.106 & 7,231 \\
\hline Fundus clinical evaluation & 15,779 & 489 & 5.787 & 0.051 & $9,621^{*}$ \\
\hline OCT & 16,115 & 825 & 5.830 & 0.095 & 8,729 \\
\hline
\end{tabular}

15. Wait for VA to drop to 70 letters or lower before initiating treatment, regardless of VA at time of detection

\begin{tabular}{|l|c|c|c|c|c|}
\hline Self-reported vision & 20,423 & & 5.580 & & \\
\hline Amsler & 20,471 & 48 & 5.591 & 0.012 & 4,159 \\
\hline Visual acuity & 20,484 & 14 & 5.578 & -0.014 & $-1,001^{* *}$ \\
\hline Fundus clinical evaluation & 20,630 & 159 & 5.597 & 0.005 & $31,014^{*}$ \\
\hline OCT & 20,651 & 181 & 5.601 & 0.009 & 19,488 \\
\hline
\end{tabular}

16. Initiating anti-VEGF treatment on the back of OCT positive findings, without confirmation with FFA

\begin{tabular}{|l|c|c|c|c|c|}
\hline Fundus clinical evaluation & 19,649 & & 5.787 & & \\
\hline Amsler & 19,751 & 103 & 5.736 & -0.051 & $-2,018^{* *}$ \\
\hline Self-reported vision & 20,198 & 549 & 5.630 & -0.156 & $-3,514^{* *}$ \\
\hline OCT & 20,403 & 754 & 5.830 & 0.044 & 17,256 \\
\hline Visual acuity & 20,444 & 42 & 5.600 & -0.230 & $-180^{* *}$ \\
\hline 17. Higher testing cost scenario \\
\hline OCT & 19,634 & \multicolumn{5}{l}{} \\
\hline Fundus clinical evaluation & 19,872 & 238 & 5.787 & -0.044 & $-5,452^{* *}$ \\
\hline Amsler & 19,987 & 353 & 5.736 & -0.095 & $-3,732^{* *}$ \\
\hline Self-reported vision & 20,372 & 738 & 5.630 & -0.200 & $-3,688^{* *}$ \\
\hline Visual acuity & 20,642 & 1008 & 5.600 & -0.230 & $-4,376^{* *}$ \\
\hline
\end{tabular}

18. Assume no further monitoring for conversion from 5 years

\begin{tabular}{|l|c|c|c|c|c|}
\hline OCT & 19,158 & & 5.770 & & \\
\hline Fundus clinical evaluation & 19,334 & 177 & 5.741 & -0.030 & $-5,966 * *$ \\
\hline Amsler & 19,455 & 297 & 5.705 & -0.066 & $-659 * *$ \\
\hline Self-reported vision & 19,844 & 686 & 5.621 & -0.149 & $-2,871^{* *}$ \\
\hline Visual acuity & 20,072 & 914 & 5.595 & -0.175 & $-3,738^{* *}$ \\
\hline
\end{tabular}

${ }^{* *}$ Dominated; * Extendedly dominated; \# ICER with respect to less costly non-dominated strategy 


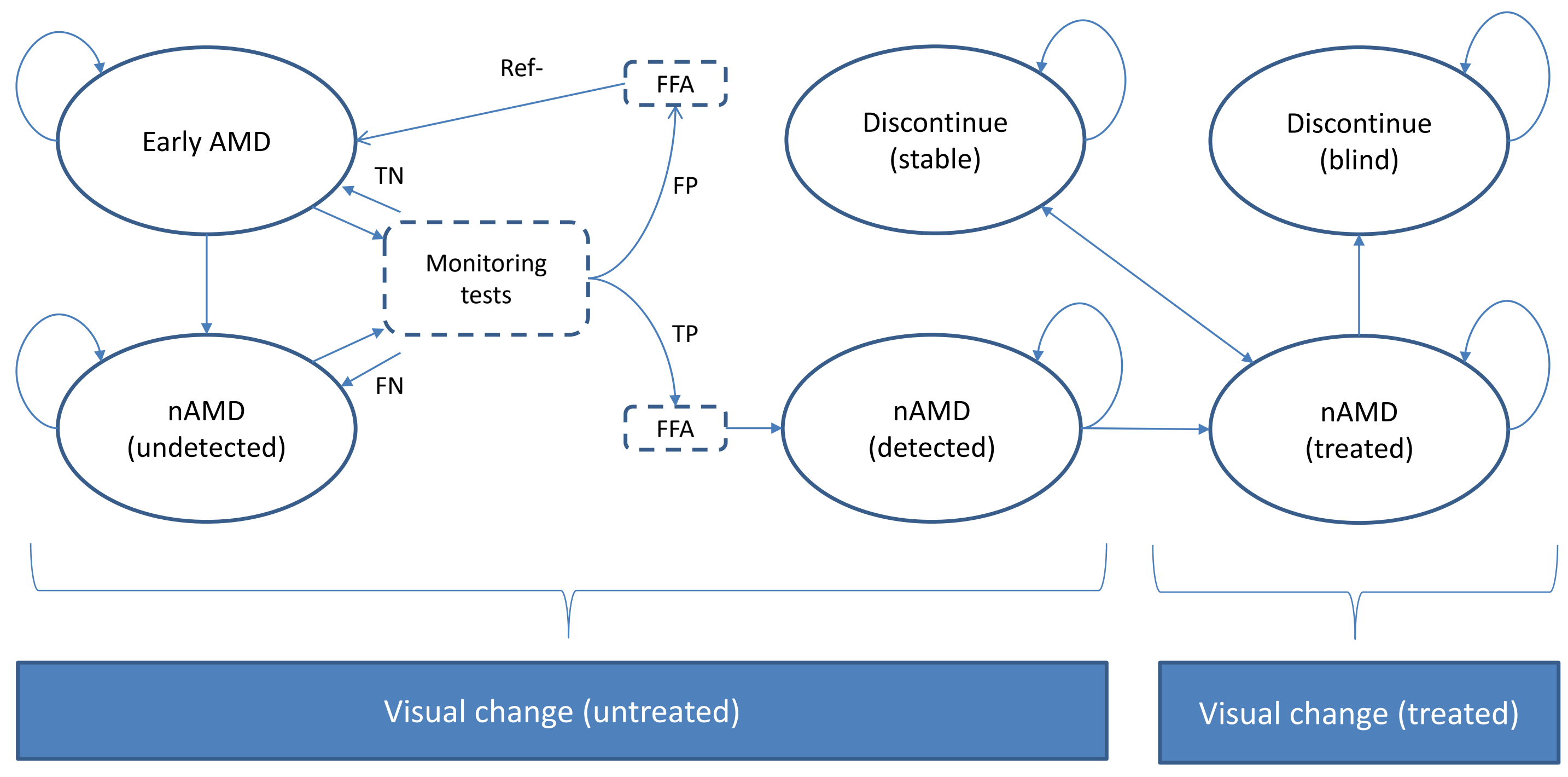




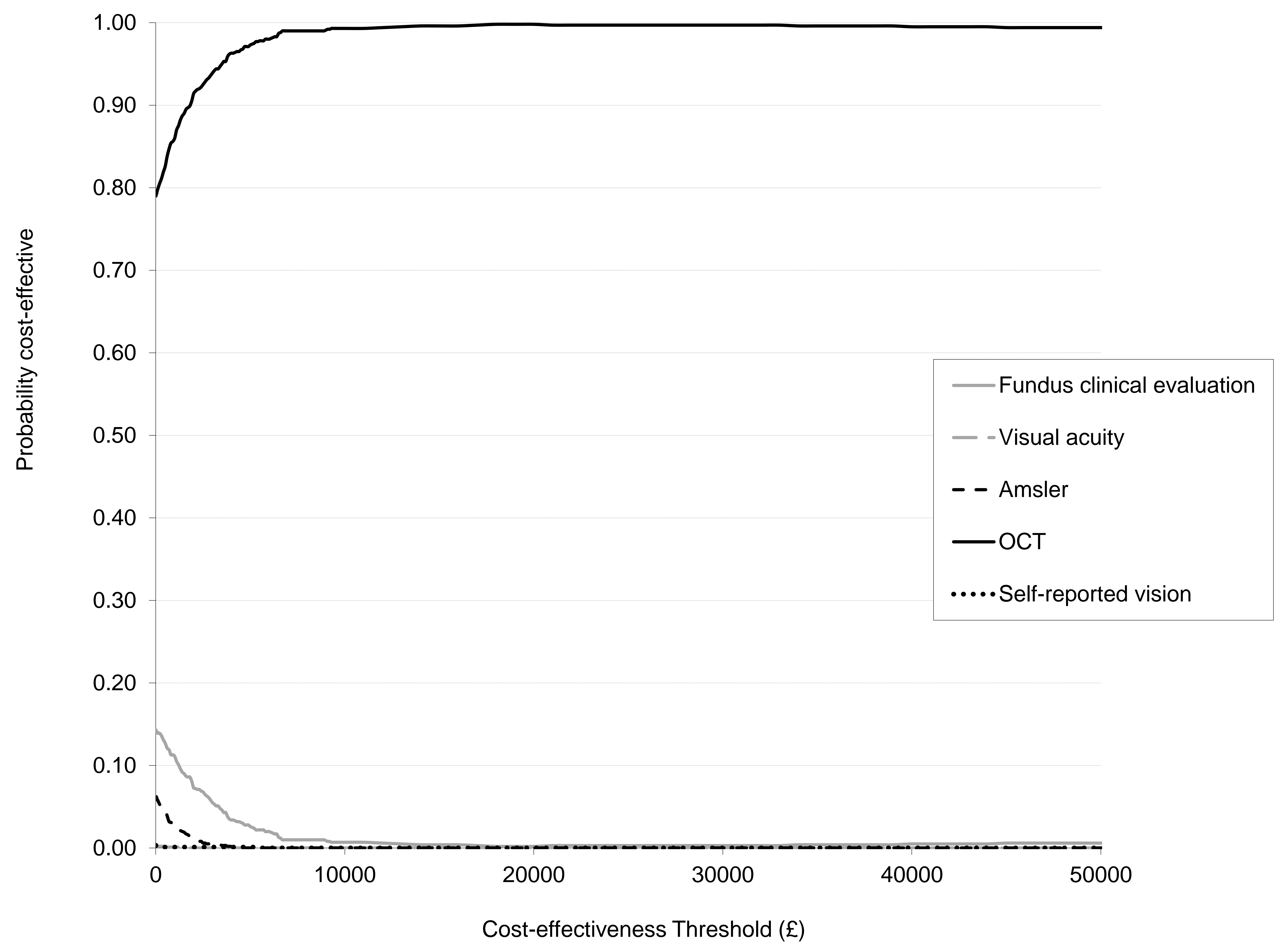




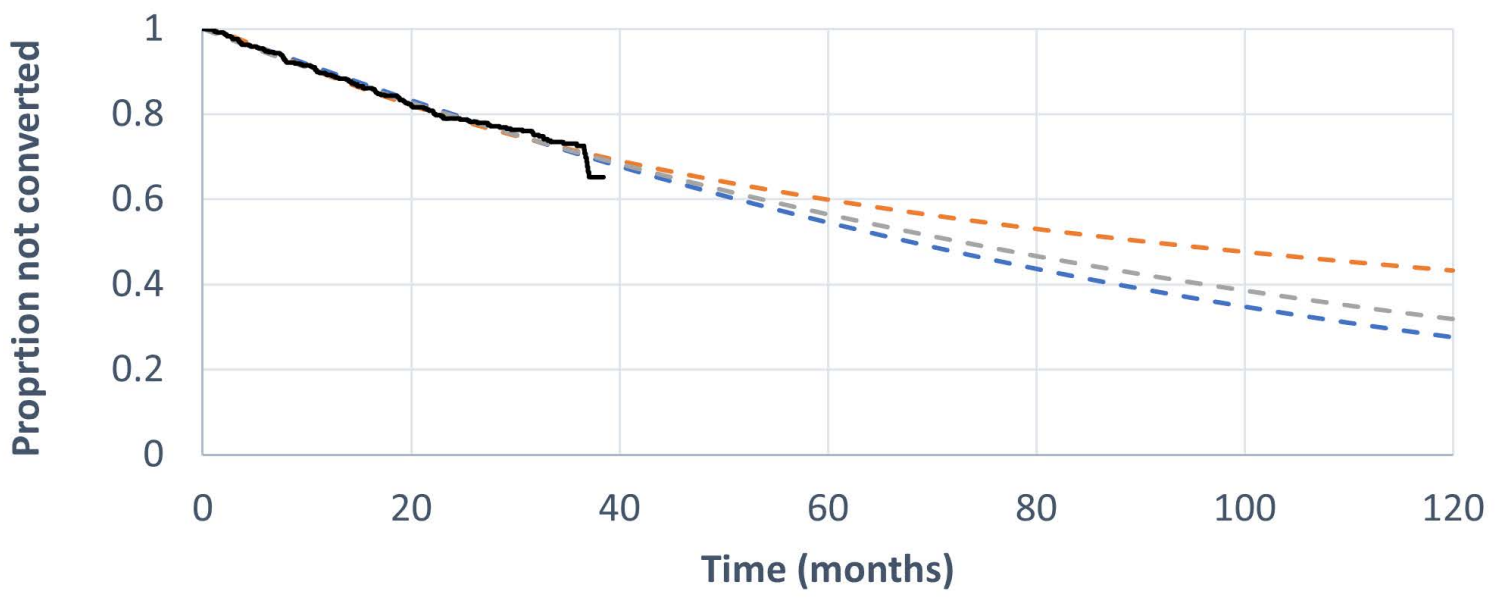

$$
\begin{array}{ll}
--- \text { Weibull extrapolation } & --- \text { Lognormal extrapolation } \\
\text { - - - Exponential extrapolation } \quad \longrightarrow \text { Kaplan_Maier data }
\end{array}
$$




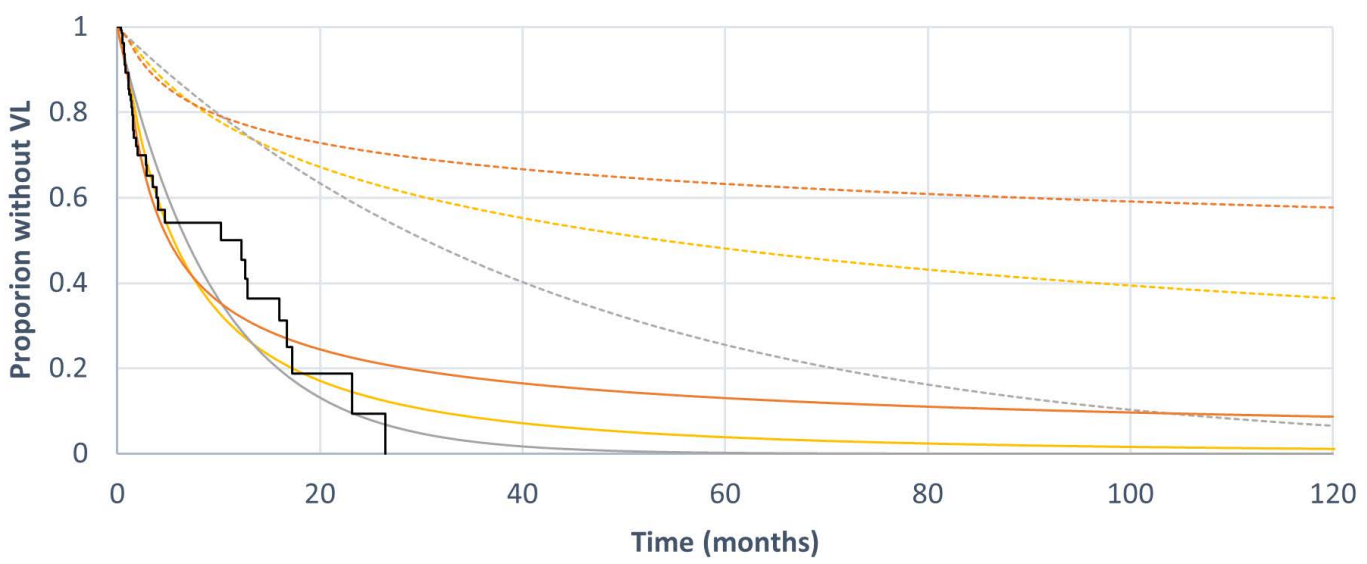

Lognormal (10 or more)

Exponential (10 or more)

Lognormal (30 or more)

Exponential (30 or more)

Generalisd gamma(30 or more)

Generalised gamma (10 or more)

Kaplan Meier (10 or more) 


\section{Visual Acuity, treated patients}

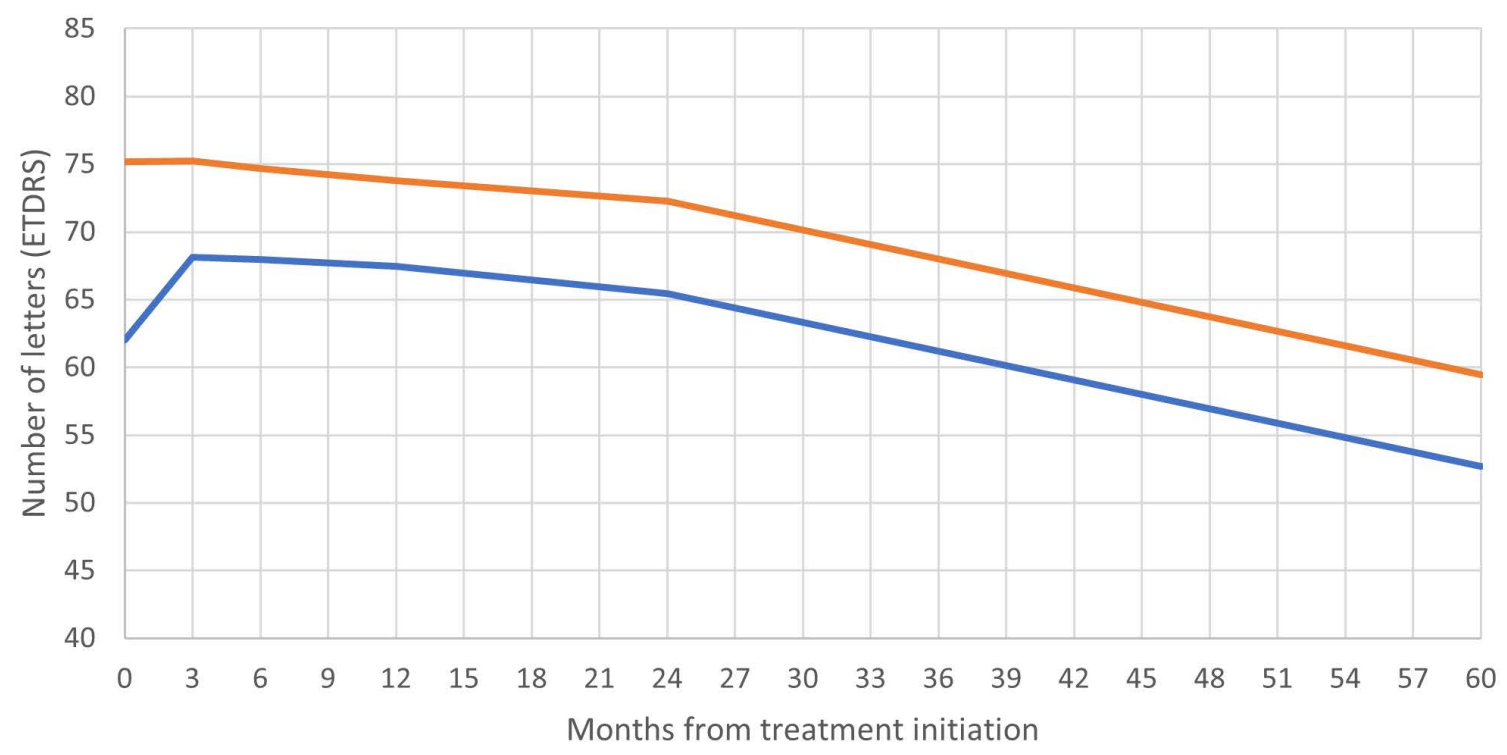

\footnotetext{
— treated after losing $\geq 10$ letters — treated before losing 10 letters
} 